\title{
A Rh-Catalyzed Cycloisomerization/Diels-Alder Cascade Reaction of 1,5-Bisallenes for the Synthesis of Polycyclic Heterocycles
}

\author{
Albert Artigas, Jordi Vila, Agustí Lledó, Miquel Solà,* Anna Pla-Quintana and Anna Roglans* \\ Institut de Química Computacional i Catàlisi (IQCC) and Departament de Química, Universitat de Girona (UdG), Facultat de \\ Ciències, C/ Maria Aurèlia Capmany, 69, 17003-Girona, Catalunya, Spain.
}

Supporting Information Placeholder

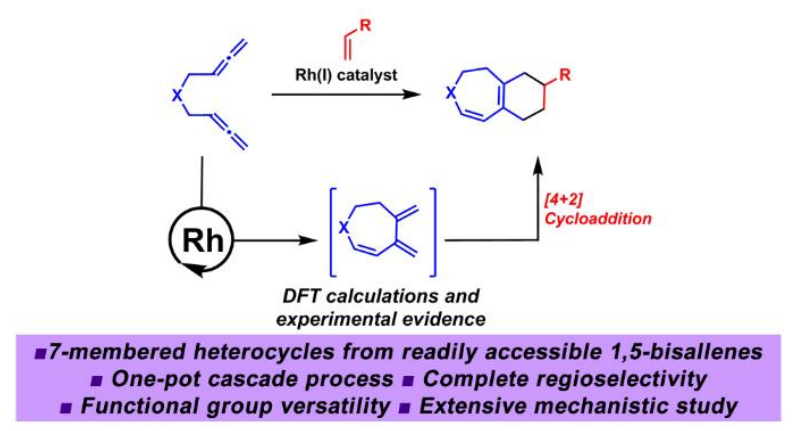

\begin{abstract}
A novel methodology to transform bisallenes into a variety of polycyclic derivatives employing rhodium(I) catalysis has been developed. This transformation encompasses an intramolecular Rh-catalyzed cycloisomerization of bisallenes $\mathbf{1}$ to deliver a reactive cycloheptadiene, which concomitantly undergoes a regioselective [4+2] cycloaddition with alkenes. A complete mechanistic study of this transformation has been undertaken including DFT calculations. Overall, the methodology presented here constitutes a new and straightforward entry to polycyclic dihydroazepine and dihydrooxepine derivatives employing catalytic methods.
\end{abstract}

Transition-metal catalyzed cyclization reactions of unsaturated compounds have an enormous synthetic potential for the preparation of a wide range of carbocyclic and heterocyclic scaffolds in a single step with perfect atom economy. ${ }^{1}$ Among the different unsaturated substrates available, increasing attention has been paid to the use of allenes, which have now become an established member of the synthetic arsenal for cyclization reactions and related processes. ${ }^{2}$ Given that allenes are cumulated systems with two contiguous carbon-carbon double bonds, the control of the chemoselectivity - i.e. which of the two double bonds reacts - makes the construction of various products from one single substrate possible. The available chemical space is obviously increased when two allene moieties are involved.

When 1,5-bisallenes are treated under catalysis by transition metals, products with 5-, 6- or 7-membered rings can be obtained. Palladium, platinum, and gold favor carbocyclization processes. Under palladium catalysis, 5-membered rings have been obtained by the groups of Ma, Yu, and Kang. ${ }^{3}$ More recently, Bäckvall and coworkers, described the formation of 7 membered rings. ${ }^{4}$ A similar trend was observed using platinum, which allowed the synthesis of products featuring 5- ${ }^{5}$ and $7-$ membered $^{6}$ rings. An unexpected example of a rare [2+2] cycloaddition of bisallenes has been described using $N$-heterocyclic carbene gold(I) catalysis to deliver 6-membered rings. ${ }^{7}$

On the other hand, rhodium-promoted cyclizations of 1,5bisallenes are postulated to proceed via oxidative cyclization.
Scheme 1. Previous studies in Rh(I)-catalysed cyclization reactions of 1,5-bisallenes
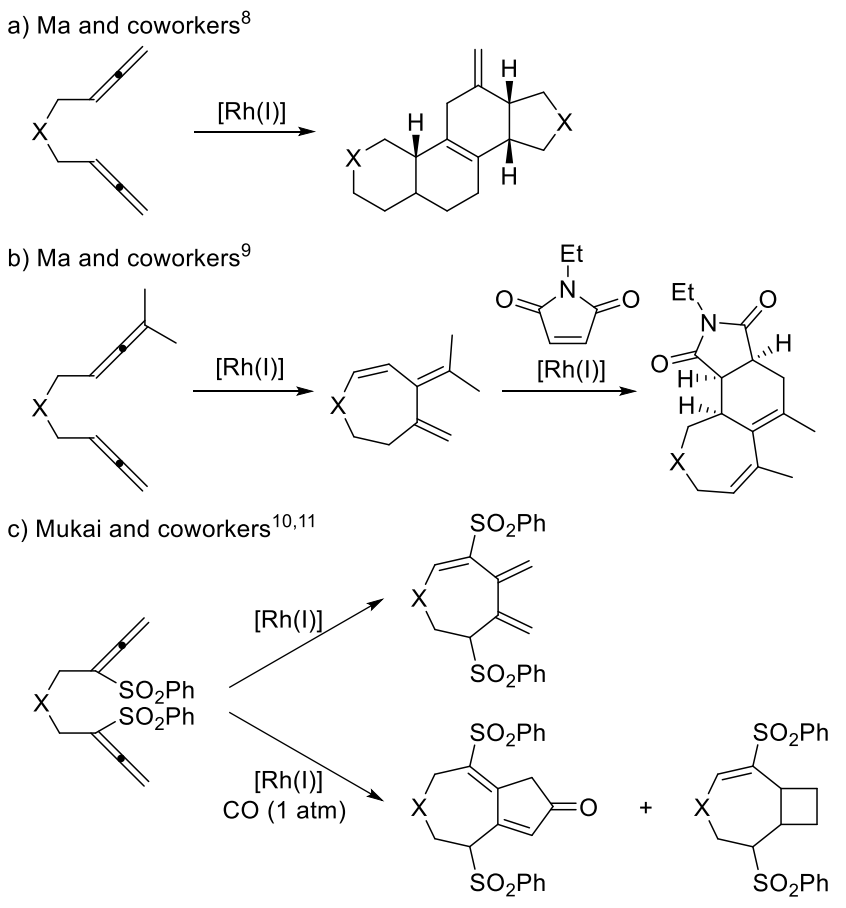
Ma and coworkers ${ }^{8}$ described a two-fold cyclization of terminal bisallene under rhodium catalysis. The mechanism was postulated to be a $[2+2+2]$ cycloaddition followed by a Diels-Alder reaction. The initial oxidative coupling can involve either the two internal double bonds or an internal and an external double bond of the two allene moieties, affording 5- or 6-membered intermediate metalacycles, respectively (Scheme 1a). The same research group ${ }^{9}$ described the synthesis of seven-membered trienes via Rh-catalyzed cycloisomerization of 1,5-bisallenes with substituents at the terminal positions (Scheme 1b). When these dienes were treated with $N$-ethyl maleimide under rhodium catalysis, the expected [4+2] adduct was not obtained, but rather a product derived from an initial isomerization of the double bonds followed by Diels-Alder cycloaddition. Mukai and coworkers ${ }^{10}$ also managed to isolate an exocyclic diene when the initial bisallene was terminal although these bisallenes had the particularity of having two $\mathrm{SO}_{2} \mathrm{Ph}$ groups at the internal carbon atom of the allene (Scheme 1c). Carbonylative [2+2+1] cycloadditions have been described by the groups of Mukai ${ }^{10,11}$ (Scheme 1c) and Chung, ${ }^{12}$ although this latter group used cobalt/rhodium heterobimetallic nanoparticles. In both cases, the authors postulated that the external double bonds of both allenes were involved in the oxidative cyclization step, affording a seven-membered scaffold. In Mukai's studies, a [2+2] cycloadduct without $\mathrm{CO}$ incorporation was usually obtained.

Azepine and oxepine-containing fused ring systems are found in some pharmacologically active compounds and in natural products, ${ }^{13}$ and their efficient synthesis is still highly challenging. Therefore, developing cycloaddition reactions of bisallenes with a third unsaturation being able to control the formation of a seven-membered ring is highly desirable. To the best of our knowledge, the Pauson-Khand-type reaction developed by Mukai ${ }^{11}$ is the only example of such a process reported to date. Given these precedents, and based on our previous experience with Rh-catalyzed cycloaddition reactions involving allenes, ${ }^{14}$ we envisaged developing a cycloaddition reaction between 1,5bisallenes and alkenes with the aim of controlling the reaction towards the synthesis of fused seven-six-membered bicyclic systems.

We started by studying the cycloaddition of $N$-tosyl-tethered bisallene $1 \mathbf{a}$ and ethyl acrylate $\mathbf{2 a}$ (see Table 1) using $10 \%$ mol of cationic rhodium complex $\left[\mathrm{Rh}(\operatorname{cod})_{2}\right] \mathrm{BF}_{4}$ with $(R)$-BINAP in THF: $\mathrm{CH}_{2} \mathrm{Cl}_{2}$ (4:1). Two different compounds were obtained: compound 3aa, with a 4-aza-bicyclo[5.4.0]undeca-1(7),2-diene skeleton, and the seven-membered cross-conjugated triene $\mathbf{4 a}$. When the bulky phosphine DTBM-Segphos was used, the yield of 3aa was improved to $65 \%$, and the yield of triene $4 \mathbf{a}$ was reduced to $5 \%$. However, $\mathbf{5 a}$, originating from the cycloisomerization of the bisallene, was obtained in $15 \%$ yield. ${ }^{15}$ Lowering the temperature to $40^{\circ} \mathrm{C}$ avoided the formation of $\mathbf{4 a}$, resulting in our optimized set of conditions (see the SI for the complete optimization study).

Having established the optimum reaction conditions, the scope of the reaction was then evaluated, as shown in Figure 1. Overall, the reaction proceeds in good to moderate yields with a wide range of alkenes. Reactions involving alkyl and aryl acrylates (2a-2f) deliver products in yields ranging between 50 $68 \%$. In some cases, by-product $\mathbf{5 a}$ was also formed and separated from the desired product by column chromatography. Vinyl alkyl ketones $\mathbf{2} \mathbf{g}$ and $\mathbf{2 h}$ also produced the corresponding cycloadducts in $72 \%$ and $75 \%$ yields, respectively. Disubstituted cyclic alkenes, such as maleimide (2i), $N$-ethyl maleimide (2j), and maleic anhydride (2k), underwent the cycloaddition reaction efficiently to produce derivatives $\mathbf{3 a i}, \mathbf{3 a j}$, and $\mathbf{3 a k}$ in excellent yields and avoiding the formation of by-product $\mathbf{5 a}$. The use of phenyl vinyl sulfone (2l) and phenyl vinyl sulfonate (2m) afforded derivatives 3al and 3am in 31\% and 60\% yields respectively and, again, no traces of $\mathbf{5 a}$. In addition, two $1 \mathrm{mmol}$ scale reactions using ethyl acrylate $\mathbf{2 a}$ and vinyl methyl ketone $\mathbf{2 g}$ were performed, affording a $69 \%$ yield of $3 \mathbf{a a}$ (15\% yield of 5a) and a $77 \%$ yield of $\mathbf{3 a g}$ (14\% yield of 5a), respectively.

Table 1. Optimization of the rhodium(I)-catalyzed cycloaddition of bisallene $\mathbf{1 a}$ with alkene $\mathbf{2} \mathbf{a}^{\mathrm{a}}$

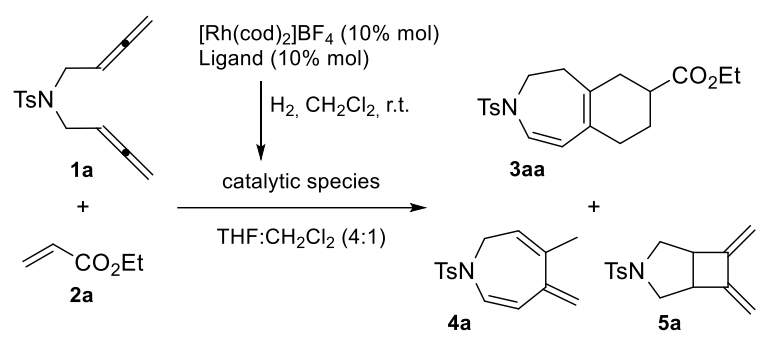

$\begin{array}{clccc}\text { Entry } & \text { Ligand } & \begin{array}{l}\text { Temperature } \\ \left({ }^{\circ} \mathbf{C}\right)\end{array} & \begin{array}{l}\text { Reaction } \\ \text { time }(\mathbf{h})\end{array} & \begin{array}{l}\text { Yield } \\ \text { 3aa / 4a / 5a }\end{array} \\ 1 & (R) \text {-BINAP } & 65 & 4 & 49 / 45 /-- \\ 2 & \begin{array}{l}(R)-D T B M- \\ \text { SegPhos }\end{array} & 65 & 4 & 65 / 05 / 15 \\ 3 & \begin{array}{l}(R)-D T B M- \\ \text { SegPhos }\end{array} & 40 & 16 & 60 /--/ 15 \\ & & & \end{array}$

Reaction conditions: $0.09 \mathrm{mmol}$ of $\mathbf{1 a}([\mathbf{1 a}]=9 \mathrm{mM}), 50$ equivalents of 2a, $10 \%$ mol of Rh catalyst in $20 \mathrm{~mL}$ of THF: $\mathrm{CH}_{2} \mathrm{Cl}_{2}(4: 1)$ at the indicated temperature and time. The $10 \%$ mol mixture of $\left[\mathrm{Rh}(\operatorname{cod})_{2}\right] \mathrm{BF}_{4}$ and phosphine was treated with hydrogen in dichloromethane $\left(\mathrm{CH}_{2} \mathrm{Cl}_{2}\right)$ solution for catalyst activation prior to substrate addition.
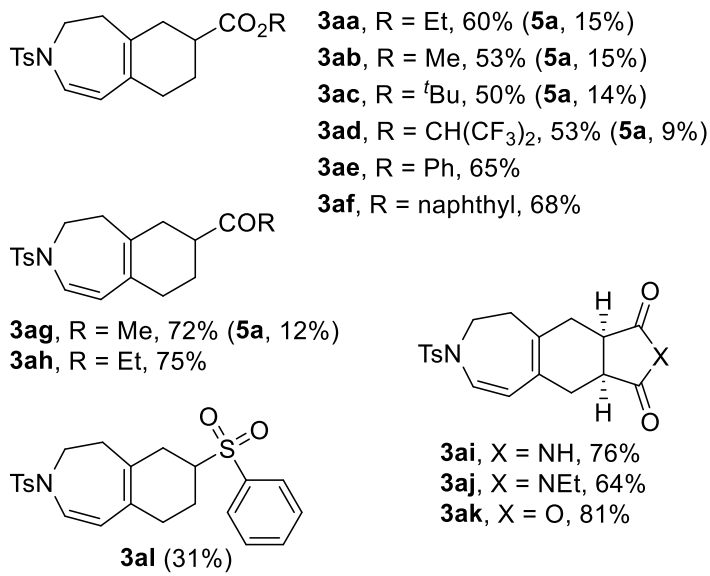

3ai, $X=\mathrm{NH}, 76 \%$ 3aj, $X=N E t, 64 \%$ 3ak, $X=0,81 \%$
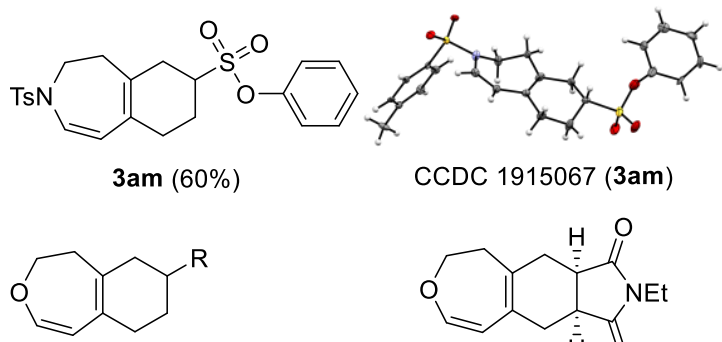

3ba, $\mathrm{R}=\mathrm{CO}_{2} \mathrm{Et}, 17 \%$

3bg, $R=$ COMe, $27 \%$

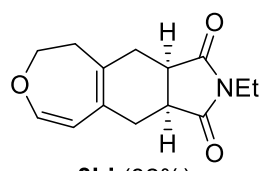

3bj $(32 \%)$

Figure 1. Scope of the cycloaddition of bisallenes 1 with alkenes 


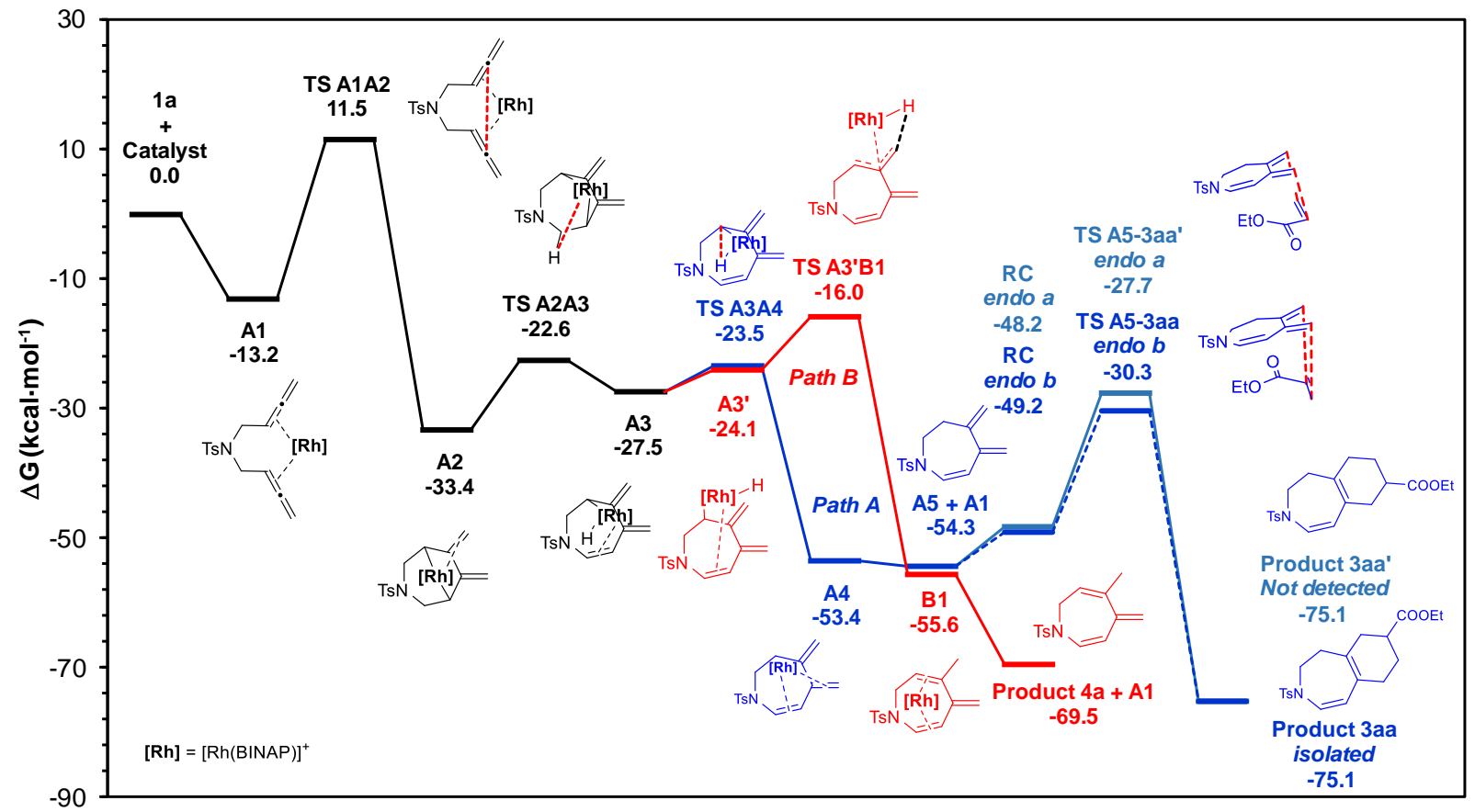

Figure 2. Gibbs energy profile for the tandem cycloisomerization/Diels-Alder cycloaddition (Path A, blue) leading to product 3aa and cycloisomerization reaction (Path $\mathrm{B}$, red) leading to product 4a. $\mathrm{RC}=$ Reactant complex

Single crystal X-ray diffraction analysis of compound 3am allowed us to unambiguously establish the structure of the cycloadduct obtained. ${ }^{16}$

To extend the methodology to other 1,5-bisallenes, oxygentethered bisallene $\mathbf{1 b}$ was prepared and reacted with three different alkenes: ethyl acrylate $\mathbf{2 a}$, methyl vinyl ketone $\mathbf{2 g}$ and $\mathrm{N}$ ethylmaleimide $\mathbf{2} \mathbf{j}$ affording the corresponding derivatives $\mathbf{3 b a}$, $\mathbf{3 b g}$ and $\mathbf{3 b j}$ in moderate yields ranging from 17 to $32 \%$.

Since a stereogenic centre was generated in derivatives $\mathbf{3}$, the enantiomeric excess was measured in all cases, but no enantioinduction was observed regardless of the substrate or the ligand used. This result is commensurate with the mechanism proposed for this transformation (vide infra).

To gain further understanding of the reaction mechanism, we completed our study by evaluating computationally the process that transforms 1a into 3aa. The Gibbs energy profile computed at $313.15 \mathrm{~K}$ and 1 atm. with the M06L-D3/cc-pVTZPP/SMD(76\% THF, 24\% $\left.\mathrm{CH}_{2} \mathrm{Cl}_{2}\right)^{17} / / \mathrm{B} 3 \mathrm{LYP}-\mathrm{D} 3 / \mathrm{cc}-\mathrm{pVDZ}-\mathrm{PP}$ method is depicted in Figure 2 and the catalytic cycle is shown in Figure 3 and the molecular structures of the TS in Figure S4. To reduce the computational effort required, BINAP was chosen as the model phosphine ligand instead of the optimal ligand $(R)$-DTBM-Segphos (see SI for a complete description of the computational methods).

The reaction starts with $\eta^{4}$-coordination of $[\mathrm{Rh}(\mathrm{BINAP})]^{+}$to the two internal double bonds of 1,5-bisallene 1a to form the square-planar 16-electron intermediate A1. This process is exergonic by $13.2 \mathrm{kcal} / \mathrm{mol}$. Upon coordination, intermediate $\mathbf{A 1}$ readily experiences oxidative coupling at the central carbon atoms of both allene moieties to deliver intermediate A2, a rhodabicyclo[3.2.1] octane complex featuring two contiguous exocyclic methylene groups. This first step has a Gibbs energy barrier of $24.7 \mathrm{kcal} / \mathrm{mol}$ through TS A1A2 and is exergonic by 20.2 $\mathrm{kcal} / \mathrm{mol}$. Intermediate $\mathbf{A} \mathbf{2}$ is an 18-electron species and shows a distorted octahedral geometry in which one of the $\mathrm{O}$ atoms of the tosyl group occupies one of the six positions $\left(\mathrm{d}_{\mathrm{Rh}-\mathrm{O}}=2.231\right.$ $\AA$ ) and one of the two exocyclic double bonds is $\eta^{2}$-coordinated to the $\mathrm{Rh}$ center $\left(\mathrm{d}_{\mathrm{Rh}-\mathrm{C}}=2.196\right.$ and $\left.2.132 \AA\right)$. The fact that internal bonds in allenes are more reactive than their external counterparts has already been reported in previous studies by our group. ${ }^{14 a . d}$ An alternative mechanism for this transformation by which a bisallylic rhodacyclopentane intermediate resulted from the initial oxidative coupling was proposed by $\mathrm{Ma}^{9}$ and by Mukai, ${ }^{10}$ although no mechanistic studies were reported. Our computational calculations seem to contradict this proposal, although care should be taken when comparing these two transformations owing to the different substitution patterns of the bisallene precursors involved.

A2 is converted into intermediate $\mathbf{A 3}$ through a $\beta$-hydride elimination mechanism. This process is slightly endergonic by $5.9 \mathrm{kcal} / \mathrm{mol}$ and has a Gibbs energy barrier of $10.8 \mathrm{kcal} / \mathrm{mol}$ (TS A2A3). The Rh center in intermediate A3 is $\eta^{2}$-coordinated to the newly formed $\mathrm{C}=\mathrm{C}$ bond, and presents a distorted tetrahedral geometry. Reductive elimination from intermediate A3 to form A4 has to surmount a barrier of $4.0 \mathrm{kcal} / \mathrm{mol}$ (TS A3A4) and releases $25.9 \mathrm{kcal} / \mathrm{mol}$. Subsequent release of the initial $\mathrm{Rh}(\mathrm{I})$ complex leads to triene intermediate A5, completing the catalytic cycle (Path A in Figures 2 and 3). Alternatively, intermediate A3 can experience a rearrangement with a rotation through the $\mathrm{C}-\mathrm{Rh}$ bond that approaches the hydride coordinated to $\mathrm{Rh}$ to one of the $\mathrm{C}=\mathrm{C}$ exocyclic double bonds giving A3' (Path B in Figures 2 and 3). Reductive elimination through TS A3'B1 has a cost of $8.1 \mathrm{kcal} / \mathrm{mol}$ and is exergonic by 31.5 $\mathrm{kcal} / \mathrm{mol}$. This alternative mechanism provides a rational explanation for the formation of compound $\mathbf{4 a}$.

On the other hand (Path A in Figure 2), the formation of intermediate $\mathbf{A 5}$ is followed by [4+2] cycloaddition with ethyl 
acrylate 2a to deliver compound 3aa. The formation of the desired reaction product 3aa has an overall reaction energy $\left(\Delta G_{r}\right)$ of $-75.1 \mathrm{kcal} / \mathrm{mol}$. Importantly, the regiochemistry of the reaction can also be explained by our computed reaction mechanism. While "endo $a$ " approximation of the dienophile (i.e. TS A5-3aa') has a Gibbs energy barrier of $26.6 \mathrm{kcal} / \mathrm{mol}$, the "endo b" approximation (i.e. TS A5-3aa) has a lower cost of 24.0 $\mathrm{kcal} / \mathrm{mol}$. Such a difference in energy $\left(\Delta \Delta \mathrm{G}^{\ddagger}=2.6 \mathrm{kcal} / \mathrm{mol}\right)$ accounts for the selective formation of the actual reaction product 3aa.

It has not escaped our attention that, in the same way that intermediate $\mathbf{A 5}$ does, intermediates $\mathbf{A 2}, \mathbf{A 3}$, and $\mathbf{A 4}$ are ripe to experience [4+2] cycloaddition with ethyl acrylate $\mathbf{2} \mathbf{a}$ before $\beta$ hydride elimination, reductive elimination or catalyst release takes place, respectively. Considering this, we computed all potential reaction paths leading to reaction product 3aa (see Figures S5, S6, and S7 in the SI). We found that all alternative reaction mechanisms analyzed have higher barriers or do not explain the observed regioselectivity.

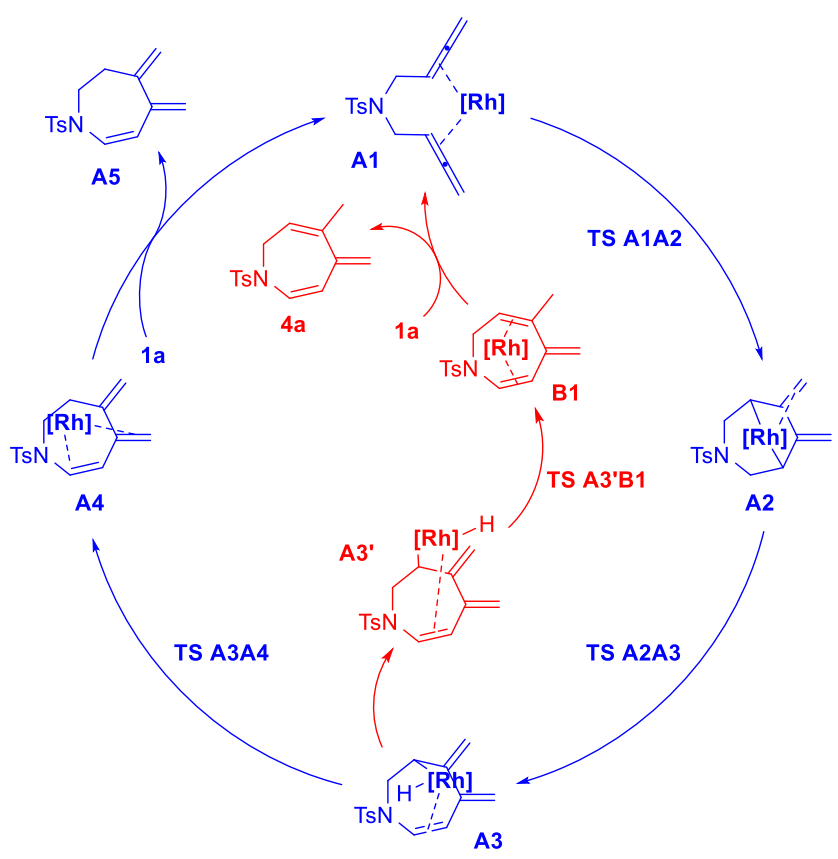

Figure 3. Catalytic cycle for the two Rh(I)-catalyzed tandem cycloisomerization reactions of 1,5-bisallene 1a leading to intermediate $\mathbf{A 5}$ (Path A, blue) and product 4a (Path B, red)

In summary, the reaction mechanisms leading to compounds A5 and 4a (paths A and B in Figure 2) have an energetic span between the turnover frequency (TOF) determining intermediate (TDI, A1) and TOF determining transition state (TDTS, TS A1A2) of $24.7 \mathrm{kcal} / \mathrm{mol} .{ }^{18}$ Once formed, intermediate $\mathbf{A 5}$ reacts with ethyl acrylate $\mathbf{2 a}$ through a regioselective catalyst-free Diels-Alder cycloaddition to provide compound 3aa.

With the aim of fully validating the proposed reaction mechanism, we completed our study by performing additional experiments. First, the involvement of reaction by-product $\mathbf{5} \mathbf{a}$ as a reaction intermediate of the catalytic cycle was ruled out by heating a mixture of this compound and ethyl acrylate 2a in the absence and presence (Schemes S4 and S5) of the rhodium catalytic mixture. In both cases, only starting materials were recovered. Computational calculations are again in good agreement with the experiments (see Figure S8 in the SI).
Finally, in an attempt to isolate intermediate A5, we performed the reaction in the absence of a dienophile (Scheme 2). Even though $\mathbf{A 5}$ could not be obtained as a stable reaction product, we found indirect evidence of its formation. Homodimer $\mathbf{6 a}$ was isolated in $58 \%$ yield, indicating that it is a promiscuous intermediate acting as both the diene and the dienophile in Diels-Alder reactions. Remarkably, only one out of the four possible isomers of the dimer was obtained. This last finding not only gives an experimental confirmation of our computational results, but opens new avenues for the preparation of complex spirocyclic compounds in a straightforward and selective manner starting from 1,5-bisallenes. The isolation by $\mathrm{Ma}$ and coworkers ${ }^{8}$ of another homodimer of $1 \mathbf{a}$ (Scheme 1a), when a different catalytic system was employed, is worth noting and highlights the importance of the coordination environment in favouring disparate mechanistic outcomes.

Scheme 2. Additional mechanistic experiments performed

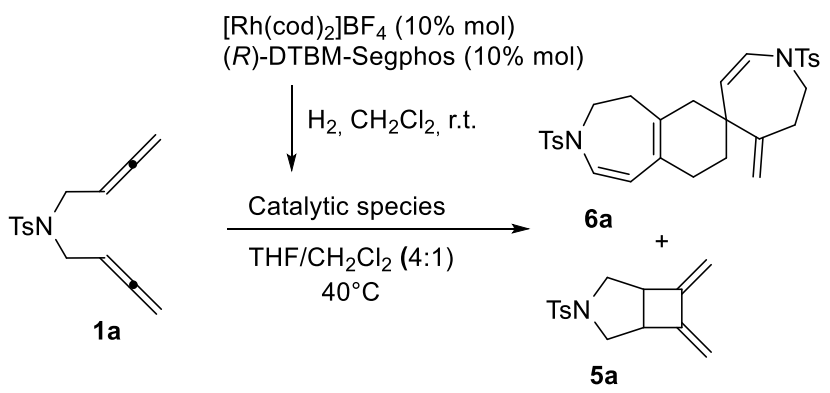

A related work by Breit and coworkers ${ }^{19}$ was described during the preparation of this manuscript, reporting on a rhodium-catalyzed cycloisomerization of 1,6-allenenes to afford six-membered ring exocyclic 1,3-dienes and further tandem Diels-Alder reaction. Our allene/allene/alkene triad of unsaturated partners, offers a much complex mechanistic scenario as exemplified by our mechanistic study, and therefore a commensurate potential for developing new reactivity manifolds.

In conclusion, we have developed an efficient cascade process based on an intramolecular Rh-catalyzed cycloisomerization of 1,5-bisallenes (1) leading to a non-isolable cycloheptadiene intermediate followed by a regioselective Diels-Alder cycloaddition with alkenes (2). The new process affords a variety of polycyclic heterocycles $\mathbf{3}$ containing dihydroazepine- and dihydrooxepine-fused ring systems. DFT calculations show that the reaction leading to $3 \mathbf{a a}$ from 1a takes place through an oxidative coupling of the rhodium at the central carbon atoms of both allenes followed by a $\beta$-hydride elimination to form intermediate A3 and reductive elimination to give intermediate A5. An uncatalyzed and regioselective Diels-Alder cycloaddition to A5 generates the final product.

\section{ASSOCIATED CONTENT}

\section{Supporting Information}

The Supporting Information is available free of charge on the ACS Publications website.

Experimental procedures, optimization of the reaction, compound characterization data, crystallographic data and computational data (PDF).

\section{AUTHOR INFORMATION}




\section{Corresponding Author}

*E-mail: miquel.sola@udg.edu

* E-mail: anna.roglans@udg.edu

\section{Present Addresses}

$\dagger$ If an author's address is different than the one given in the affiliation line, this information may be included here.

\section{Author Contributions}

The manuscript was written through contributions of all authors. / All authors have given approval to the final version of the manuscript.

\section{Notes}

The authors declare no competing financial interest.

\section{ACKNOWLEDGMENT}

We are grateful for the financial support by the Spanish Ministry of Economy and Competitivity (MINECO) (Projects CTQ201785341-P and CTQ2017-83587-P, FI predoctoral grant to A.A., RyC contract RYC2012-11112 to A.L.), the Generalitat de Catalunya (Project 2017-SGR-39, Xarxa de Referència en Química Teòrica i Computacional, ICREA Academia 2014 prize for M.S.) and UdG for IF predoctoral grant to J.V.

\section{REFERENCES}

(1) For selected reviews, see: (a) Kotha, S.; Lahiri, K.; Sreevani, G. Design and synthesis of aromatics through $[2+2+2]$ cyclotrimerization. Synlett 2018, 29, 2342-2361. (b) Yamamoto, Y. Recent topics of Cp*RuCl-catalyzed annulation reactions. Tetrahedron Lett. 2017, 58, 3787-3794. (c) Neuhaus, J.D.; Willis, M.C. Homogeneous rhodium(I)-catalysis in de novo heterocycle synthesis. Org. Biomol. Chem. 2016, 14, 4986-5000. (d) Omae, I. Characteristic reactions of group 9 transition metal compounds in organic synthesis. Appl. Organometal. Chem. 2009, 23, 91-107. (e) Michelet, V.; Toullec, P.Y.; Genêt, J.-P. Cycloisomerization of $1, n$-enynes: challenging metal-catalyzed rearrangements and mechanistic insights. Angew. Chem. Int. Ed. 2008, 47, 4268-4315.

(2) For selected and recent reviews, see: (a) Lledó, A.; Pla-Quintana, A.; Roglans, A. Allenes, versatile unsaturated motifs in transition-metal-catalysed $[2+2+2]$ cycloaddition reactions. Chem. Soc. Rev. 2016, 45, 2010-2023; (b) Alcaide, B.; Almendros, P.; Aragoncillo, C. Cyclization reactions of bis(allenes) for the synthesis of polycarbo(hetero)cycles. Chem. Soc. Rev. 2014, 43, 3106-3135. (c) Kitagaki, S.; Inagaki, F.; Mukai, C. $[2+2+1]$ Cyclization of allenes. Chem. Soc. Rev. 2014, 43, 2956-2978. (d) López, F.; Mascareñas, J.L. [4+2] and [4+3] Catalytic cycloadditions of allenes. Chem. Soc. Rev. 2014, 43, 2904-2915. (e) Ye, J.; Ma, S. Palladium-catalyzed cyclization reactions of allenes in the presence of unsaturated carbon-carbon bonds. Acc. Chem. Res. 2014, 47, 989-1000. (f) López, F.; J.L. Mascareñas. Allenes as three-carbon units in catalytic cycloadditions: new opportunities with transition-metal catalysts. Chem. Eur. J. 2011, 17, 418-428. (g) Aubert, C.; Fensterbank, L.; Garcia, P.; Malacria, M.; Simonneau, A. Transition metal catalyzed cycloisomerizations of 1,n-allenynes and allenenes. Chem. Rev. 2011, 111, 1954-1993. (h) Chen, G.; Jiang, X.; Fu, C.; Ma, S. The diversified reactivities of 1,5-bisallenes. Chem. Lett. 2010, 39, 78-81.

(3) (a) Jiang, X.; Cheng, X.; Ma, S. Controllable [2+2] cycloadditions of 1,5-bisallenyl-substituted compounds. Angew. Chem. Int. Ed. 2006, 45, 8009-8013. (b) Hong, Y.-T.; Yoon, S.-K.; Kang, S.-K.; Yu, C.-M. A stereoselective carbocyclization of bis(allenes) with germylstannane catalyzed by palladium complexes. Eur. J. Org. Chem. 2004, 4628-4635. (c) Kang, S. K.; Baik, T. G.; Kulak, A. N.; Ha, Y. H.; Lim, Y.; Park, J. Palla- dium-catalyzed carbocyclization/silastannylation and distannylation of bis(allenes). J. Am. Chem. Soc. 2000, 122, 11529-11530.

(4) (a) Zhu, C.; Yang, B.; Qiu, Y.; Bäckvall, J.-E. Highly selective construction of seven-membered carbocycles by olefin-assisted palladium-catalyzed oxidative carbocyclizationalkoxycarbonylation of bisallenes. Angew. Chem. Int. Ed. 2016, 55, 14405-14408. (b) Zhu, C.; Yang, B.; mai, B.K.; Palazzotto, S.; Qiu, Y.; Gudmundsson, A.; Ricke, A.; Himo, F.; Bäkcvall, J.-E. Highly selective palladium-catalyzed hydroborylative carbocyclization of bisallenes to seven-membered rings. J. Am. Chem. Soc. 2018, 140, 14324-14333.

(5) Lim, Y.N.; Kim, H.-T.; Yoon, H.-S.; Jang, H.-Y. Regio- and stereoselective reductive cyclization of 1,5-bisallenes under hydrogenation conditions. Bull. Korean Chem. Soc. 2011, 32, 3117-3119.

(6) Quirós, M.T.; Hurtado-Rodrigo, C.; Muñoz, M.P. Nucleophile dependent formation of 6-and 7-membered $N$-heterocycles by platinum-catalysed cyclisation of 1,5-bisallenes. Org. Biomol. Chem. 2017, 15, 6731-6737.

(7) Kim, S. M.; Park, J. H.; Kang, Y. K.; Chung, Y. K. N-heterocyclic carbene gold(I) catalyzed transformation of $N$-tethered 1,5-bisallenes to 6,7-dimethylene-3-azabicyclo[3.1.1]heptanes. Angew. Chem. Int. Ed. 2009, 48, 4532-4535.

(8) (a) Ma, S.; Lu, P.; Lu, L.; Hou, H.; Wei, J.; He, Q.; Gu, Z.; Jiang, X.; Jin, X. What can a metal catalyst do with allenes? One-step formation of steroid scaffolds from readily available starting materials. Angew. Chem. Int. Ed. 2005, 44, 5275-5278. (b) Ma, S.; Lu, L. Rh ${ }^{\mathrm{I}}$-catalyzed bimolecular cyclization between two different 1,5-bisallenes: a combinatorial one-step approach to heterosteroids and mechanistic implications. Chem. Asian J. 2007, 2, 199-204. (c) Lu, P.; Ma, S. Rh-catalyzed triple allene approach to bicycle[4.4.0]decene derivatives and its application for the stepwise synthesis of steroid-like tetracyclic skeletons. Org. Lett. 2007, 9, 5319-5321.

(9) (a) Lu, P.; Ma, S. Observation of new cycloisomerization pattern of 1,5-bisallenes. catalyst and substituent effects. Org. Lett. 2007, 9, 2095-2097. (b) Lu, P.; Kuang, J.; Ma, S. Carboncarbon double-bond isomerization and Diels-Alder reaction of dimethyl 5-methylene-4-isopropylidene-2-cycloheptene-1,1dicarboxylate with dienophiles. SynLett 2010, 227-230.

(10) Kawamura, T.; Inagaki, F.; Narita, S.; Takahashi, Y.; Hirata, S.; Kitagaki, S.; Mukai, C. Rhodium(I)-catalyzed intramolecular carbonylative $[2+2+1]$ cycloadditions and cycloisomerizations of bis(sulfonylallene)s. Chem. Eur. J. 2010, 16, 51735183.

(11) Inagaki, F.; Narita, S.; Hasegawa, T.; Kitagaki, S.; Mukai, C. Rhodium(I)-catalyzed intramolecular carbonylative $[2+2+1]$ cycloaddition of bis(allene)s: bicyclo[6.3.0]undecadienones and bicyclo[5.3.0]decadienones. Angew. Chem. Int. Ed. 2009, 48, 2007-2011.

(12) Park, J. H.; Kim, E.; Kim, H.-M.; Choi, S. Y.; Chung, Y. K. Cobalt/rhodium heterobimetallic nanoparticle-catalyzed carbonylative $[2+2+1]$ cycloaddition of allenes and bisallenes to Pauson-Khand-type reaction products. Chem. Commun. 2008 , 2388-2390.

(13) For selected reviews, see: (a) Meyer, A.G.; Bissember, A.C.; Hyland, C.J.T.; Williams, C.C.; Szabo, M.; Abel, S.-A.G.; Bird, M.J.; Hyland, I.K.; Pham, H. Seven-membered rings, chapter 7 in Progress in Heterocyclic Chemistry, 2018, 30, 493-550. (b) Nguyen, T.V.; Hartmann, J.M.; Dieter, E. Recent synthetic strategies to access seven-membered carbocycles in natural product synthesis. Synthesis 2013, 845-873. (c) Riley, D.L.; van Otterlo, W.A.L. Oxepines and azepines, chapter 15 in Heterocycles in Natural Product Synthesis, 2011, WileyVCH, Weinheim, Germany. (d) Kantorowski, E.J.; Kurth, M.J. Expansion to seven-membered rings. Tetrahedron 2000, 56, 4317-4353. (e) Liu, J.-h.; Steigel, A.; Reininger, E.; Bauer, R. Two new prenylated 3-benzoxepin derivatives as cyclooxygenase inhibitors from Perilla frutescens var. acuta. J. Nat. Prod. 2000, 63, 403-405. Selected and recent studies based on the 
synthesis of benzo[ $[d]$ azepine derivatives: (f) Jiang, B.; Liu, J.X.; Wei, Y.; Shi, M. Nickel-catalyzed synthesis of benzo $[b]$ naphthol[ $[1,2-d]$ azepine via intramolecular radical tandem cyclization of alkyl bromide-tethered alkylidenecyclopropanes. Org. Lett. 2018, 20, 6229-6233. (g) Nayak, M.; Kang, Y.K.; Kim, I. Altering the cyclization modes: temperature-dependent intramolecular 7-endo-dig vs 6-endo-dig electrophilic ring closures. Org. Lett. 2017, 19, 1474-1477. (h) Adamovskyi, M.I.; Ryabukhin, S.V.; Sibgatulin, D.A.; Rusanov, E.; Grygorenko, O.O. Beyond the five and six: evaluation of seven-membered cyclic anhydrides in the Castagnoli-Cushman reaction. Org. Lett. 2017, 19, 130-133.

(14) (a) Cassú, D.; Parella, T.; Solà, M.; Pla-Quintana, A.; Roglans, A. Rhodium-catalyzed $[2+2+2]$ cycloaddition reactions of linear allene-ene-ynes to afford fused tricyclic scaffolds: insights into the mechanism. Chem. Eur. J. 2017, 23, 14889-14899. (b) Haraburda, E.; Fernández, M.; Gifreu, A.; Garcia, J.; Parella, T.; Pla-Quintana, A.; Roglans, A. Chiral induction in intramolecular Rhodium-catalyzed [2+2+2] cycloadditions of optically active allene-ene/yne-allene substrates. Adv. Synth. Catal. 2017, 359, 506-512. (c) Haraburda, E.; Lledó, A.; Roglans, A.; Pla-Quintana, A. Dehydrogenative $[2+2+2]$ cycloaddition of cyano-yne-allene substrates: convenient access to 2,6-naphthyridine scaffolds. Org. Lett. 2015, 17, 2882-2885. (d) Haraburda, E.; Torres, Ò.; Parella, T.; Solà, M.; Pla-Quintana, A. Stereoselective Rhodium-catalysed [2+2+2] cycloaddition of linear allene-ene/yne-allene substrates: reactivity and theoretical mechanistic studies. Chem. Eur. J. 2014, 20, 5034-5045. For a review, see : (e) Pla-Quintana, A.; Roglans, A. Chiral induction in $[2+2+2]$ cycloaddition reactions. Asian J. Org. Chem. 2018, 7, 1706-1718.

(15) Compound 5a was synthesized by $\mathrm{Ma}$ and coworkers [see reference 3a] though a palladium(0)-catalyzed [2+2] cycloaddition of bisallene 1a.

(16) CCDC 1915067 (compound 3am) contains the supplementary crystallographic data for this paper. These data can be obtained free of charge from The Cambridge Crystallographic Data Centre via www.ccdc.cam.ac.uk/data request/cif. The thermal ellipsoids in the ORTEP plot of the X-ray structure of 3am are drawn at $50 \%$ probability.

(17) $\left(76 \% \mathrm{THF}, 24 \% \mathrm{CH}_{2} \mathrm{Cl}_{2}\right)$ is equivalent to a $4: 1 \mathrm{v} / \mathrm{v}$ ratio of THF: $\mathrm{CH}_{2} \mathrm{Cl}_{2}$.

(18) (a) Kozuch, S.; Shaik, S. Kinetic-quantum chemical model for catalytic cycles: the Haber-Bosch process and the effect of reagent concentration. J. Phys. Chem. A 2008, 112, 6032-6041. (b) Kozuch, S.; Shaik, S. How to conceptualize catalytic cycles? The energetic span model. Acc. Chem. Res. 2010, 44, 101-110.

(19) Zhou, Y.; Nikbakht, A.; Bauer, F.; Breit, B. Rhodium catalyzed cycloisomerization and tandem Diels-Alder reaction for facile access to diverse bicyclic and tricyclic heterocycles. Chem. Science 2019, DOI: 10.1039/C9SC00980A. 